\title{
NATURAL SELECTION AT WORK? VITAMIN D DEFICIENCY RATES AND RISING HEALTH PROBLEMS IN YOUNG TURKISH CYPRIOT PROFESSIONALS
}

\author{
Emine Kandemiş ${ }^{1}$, Gülten Tuncel2 ${ }^{2}$, Umut Fahrioğlư ${ }^{2,3}$, Şehime Gülsün Temel ${ }^{4}$, Gamze Mocann ${ }^{3,5}$, Mahmut Çerkez \\ Ergören ${ }^{2,6}$ \\ ${ }^{1}$ Department of Molecular Biology and Genetics, Faculty of Engineering and Natural Sciences, Bahçeşehir University, Istanbul, Turkey \\ ${ }^{2}$ DESAM Institute, Near East University, Nicosia, Cyprus \\ ${ }^{3}$ Department of Medical Biology, Faculty of Medicine, Near East University, Nicosia, Cyprus \\ ${ }^{4}$ Department of Medical Genetics, Faculty of Medicine, Bursa Uludag University, Bursa, Turkey \\ ${ }^{5}$ Department of Medical Pathology, Faculty of Medicine, Near East University, Nicosia, Cyprus \\ ${ }^{6}$ Department of Medical Genetics, Faculty of Medicine, Near East University, Nicosia, Cyprus
}

\section{SUMMARY}

Objectives: Vitamin $\mathrm{D}$ is a fat-soluble, prohormone vitamin that is important especially for bone mineralization and skeletal health. In recent years, vitamin D deficiency appeared as a worldwide problem, affecting many people in different ways including the Northern Cypriot population. The deficiency might be caused by the lack of exposure to sunlight, diet low in vitamin D, sedentary lifestyle, and also due to some genetic variations in the vitamin $\mathrm{D}$ receptor (VDR) gene.

Methods: In this study, four common VDR polymorphisms and associations with vitamin D deficiency in the Turkish Cypriot population between ages $18-40$ and working in office conditions was studied by PCR- RFLP analysis.

Results: rs2228570 C>T variant was shown to be significantly associated with low serum vitamin D levels in the studied population.

Conclusion: Together with the effect of rs2228570 C>T variant in the VDR gene, it is thought that the lifestyle changes in the Turkish Cypriot population might have caused the increased frequency of vitamin $\mathrm{D}$ deficiency in the young professionals.

Key words: vitamin D deficiency, VDR, polymorphism, young professionals, Turkish Cypriots

Address for correspondence: M. C. Ergören, Near East University, Faculty of Medicine, Department of Medical Biology, 99138 Nicosia, Cyprus. E-mail: mahmutcerkez.ergoren@neu.edu.tr

https://doi.org/10.21101/cejph.a6117

\section{INTRODUCTION}

Vitamin D is identified as a fat-soluble vitamin and a lipophilic steroid pro-hormone. Vitamin D has common role in the human body and regulates calcium homeostasis, phosphorus homeostasis, and musculoskeletal health $(1,2)$. Vitamin D deficiency is a major global public health issue and causes diseases such as diabetes, cancer, cardiovascular diseases, autoimmune diseases, and depression (3-6). It helps the bones to develop, reduces the risk of colon and breast cancer, helps control infections, plays an important role in calcium absorption, prevents bone loss in older ages, prevents rickets in large quantities, and provides calcium storage in the bones (7-10). Vitamin $D$ is taken in two ways: nutrition and sunlight. It can be taken with external nutrients or it can be produced in the body with the help of sunrays. Liver and kidneys are common organs for transforming of vitamin D to its precursor form. After absorption, liver transforms vitamin D into 25-hydroxyvitamin D. 25-hydroxyvitamin $\mathrm{D}$ is a necessary precursor to the active form. Then the kidneys transform 25-hydroxyvitamin D to 1,25-hydroxyvitamin D; 1,25 -hydroxyvitamin $\mathrm{D}$ is the active form of Vitamin $\mathrm{D}$ in the body. If the individuals have a disease related to liver or kidney, they can have vitamin D deficiency (2). Vitamin D deficiency depends on age and disease, also may be related to populations. For example infants, adult and elderly individuals have vitamin D deficiency at different rate in different populations (11). African Americans and Hispanics are dark skinned and have increased amounts of melanin in their skin, which negatively affects absorption of vitamin D. Therefore, African Americans and Hispanics have vitamin D deficiency (2). Light-skinned individuals should be exposed to the noon sun every day for at least 30 minutes in order to maintain health and produce sufficient amounts of vitamin D from sunlight. In most of these climates, this is not possible for an average of 6 months each year, and even using sunscreen to get protection from UV rays prevents vitamin D production in the skin. African Americans and other dark-skinned people need 6 times the amount they are exposed to, to make enough vitamin D. 
Vitamin D deficiency was associated with cancers including colon, breast, prostate, ovary, kidney, bladder, gall bladder, and lymphomas $(12,13)$. William Grant reported that in 2007257,000 cancer deaths in the United States were due to vitamin D deficiency. As the distance from the dish increased, cancer cases also increased. Evidence suggests that vitamin D supplementation may help patients to recover (14). It is also thought that skin pigmentation is affected by lack of vitamin $\mathrm{D}$ in humans and white colour may be formed by natural selection (15). D vitamins possess potent anti-inflammatory properties and may destroy free radicals that cause cellular damage. Vitamin D deficiencies are involved in many autoimmune disorders including multiple sclerosis, lupus, Crohn's disease, rheumatoid arthritis and psoriasis. Vitamin D supplementation helps improve autoimmune conditions such as diabetes mellitus (16).

People in the westernized world are more exposed to open spaces, shopping centres, plazas, and so on. The majority of the population moved to cities and began to live their lives in enclosed spaces. Today, people are now beginning to see the rays of the sun as something to be feared and protected from it. And people with mutations are beginning to feel more vitamin D deficiency because they are less exposed to sunlight. Thus, the current study was carried out on the Turkish Cypriot population, which were notified rich in vitamin D deficiency, aiming to detect frequency of variations on the vitamin D receptor (VDR) gene that might have a role in increased frequency of vitamin $\mathrm{D}$ deficiency in the younger population.

\section{MATERIALS AND METHODS}

One hundred and thirty-one Turkish Cypriot individuals, ages ranging from 18 to 40, participated in this study. All subjects were office workers. The only specific criteria of selecting the subjects was body mass index. Individuals with BMI $>30$ were excluded. The protocol was approved by the Institutional Ethics Review Board (NEU/2019/70/857). Informed consent was obtained from all participants.

\section{Biochemical Analysis}

Liaison ${ }^{\circledR} 25-\mathrm{OH}$ vitamin D assay (Diasorin, Stillwater, MN) was used to quantify the serum vitamin D levels, following the separation of blood cells by centrifugation within 24 hours of sample collection. Accepted ranges for the $25-\mathrm{OH}$ vitamin D status are: $<10 \mathrm{ng} / \mathrm{ml}$ : severe deficiency; $10-20 \mathrm{ng} / \mathrm{ml}$ : deficiency; 20-29 ng/ml: insufficiency; 30-100 ng/ml: sufficiency; and $>100 \mathrm{ng} / \mathrm{ml}$ : toxicity.

\section{Genotyping}

Three millilitres of venous blood were drawn into a sterile tube containing ethylenediaminetetraacetic acid (EDTA) and stored at $+4{ }^{\circ} \mathrm{C}$ until the isolation of genomic DNA. Total genomic DNA was extracted from peripheral blood samples following manufacturer's protocol (Hibrigen, Istanbul, Turkey). Polymerase chain reaction (PCR) followed by restriction fragment-length polymorphism (RFLP) analyses were performed to obtain the genotypes of vitamin D variants (rs2228570, rs731236, rs1544410, rs7975232) according to previously used protocols $(17,18)$. The digested fragments were separated in $3 \%$ agarose gel and visualized by ethidium bromide staining.

\section{Statistical Analysis}

Statistical analysis was performed using GraphPad Software, Inc. California, USA, and data were expressed as mean \pm standard deviation (SD). Intergroup significance between the genotypes in the Turkish Cypriot population was evaluated by Student's T-test and $\chi^{2}$ analysis. Allelic frequencies were calculated by genotypic distribution of polymorphisms; each variant was tested for the Hardy-Weinberg equilibrium (HWE). Statistical significance was assumed when $\mathrm{p}$-value was $<0.05$.

\section{RESULTS}

\section{Characteristics of the Studied Group}

A total of 131 participants, $48 \%$ males and 52\% females, volunteered in this study. No significant difference between the gender of participants was detected. All were unrelated, Turkish Cypriots from different parts of the island. Average age of the subjects was $30.1 \pm 5.1$ and they were free-living young professionals working in their office from nine to five during weekdays. Average serum vitamin D level of the participants was $27.4 \pm 8.5$.

All individuals underwent regular check-up tests and medical examinations by physicians and they were classified as healthy with no systemic diseases. All subjects were middle-class workers who are exposed to adequate amount of daily sunlight.

\section{Genotype and Allele Distributions of VDR Gene Polymorphisms}

Genotype distributions and allele frequencies of the studied VDR gene polymorphisms (rs1544410 G>A, rs2228570 C $>$ T, rs7975232 $\mathrm{A}>\mathrm{C}$ and $\mathrm{rs} 731236 \mathrm{~T}>\mathrm{C}$ ) are shown in Table 1. Distributions of all genotypes were in agreement with the HardyWeinberg equilibrium (HWE $\mathrm{p}>0.05$ ). Frequencies of the minor alleles were found to be 0.31 for rs $1544410 \mathrm{~A}, 0.39$ for rs 2228570 $\mathrm{T}, 0.25$ for $\mathrm{rs} 7975232 \mathrm{C}$, and 0.37 for rs $731236 \mathrm{C}$.

\section{Comparison of VDR Gene Polymorphisms with Se- rum Vitamin D Levels}

The serum vitamin D (25-OH vitamin D) level of individuals carrying each studied VDR polymorphism is shown in Table 2. Determination of significant associations between the most common allele and minor allele heterozygote and homozygote individuals' serum vitamin D level was performed by ANOVA standard weighted-means analysis for independent samples. A significant association between carrying the T allele of rs2228570 variation and having low levels of vitamin D levels was detected $(p=0.029)$. No significant association was detected for rs 731236 $\mathrm{T}>\mathrm{C}(\mathrm{p}=0.683), \mathrm{rs} 1544410 \mathrm{G}>\mathrm{A}(\mathrm{p}=0.098)$, and $\mathrm{rs} 7975232 \mathrm{~A}>\mathrm{C}$ $(\mathrm{p}=0.128)$. 
Table 1. Genotype and allele distributions of VDR gene polymorphisms $(N=131)$

\begin{tabular}{|c|c|c|c|c|c|}
\hline SNP & Genotype/allele & $\mathrm{n}(\%)$ & SNP & Genotype/allele & $\mathrm{n}(\%)$ \\
\hline \multirow{5}{*}{ rs2228570 } & $\mathrm{CC}$ & $76(58.0)$ & \multirow{5}{*}{ rs731236 } & TT & $49(37.4)$ \\
\hline & CT & $47(35.8)$ & & $\mathrm{TC}$ & 67 (51.1) \\
\hline & TT & $8(6.2)$ & & $\mathrm{CC}$ & $15(11.4)$ \\
\hline & C & $199(61.1)$ & & $\mathrm{T}$ & $165(62.9)$ \\
\hline & $T$ & $63(38.9)$ & & C & $97(37.1)$ \\
\hline$x^{2}$ & & 0.04 & $x^{2}$ & & 1.41 \\
\hline HWE p-value & & 0.841 & HWE p-value & & 0.235 \\
\hline \multirow{5}{*}{ rs1544410 } & GG & $64(48.8)$ & \multirow{5}{*}{ rs7975232 } & AA & $70(53.4)$ \\
\hline & GA & $53(40.4)$ & & $A C$ & $56(42.7)$ \\
\hline & AA & $14(10.6)$ & & $\mathrm{CC}$ & $6(4.5)$ \\
\hline & G & $181(69.0)$ & & A & $196(74.8)$ \\
\hline & A & $81(31.0)$ & & C & $68(25.2)$ \\
\hline$x^{2}$ & & 0.37 & $x^{2}$ & & 1.58 \\
\hline HWE p-value & & 0.534 & HWE p-value & & 0.208 \\
\hline
\end{tabular}

SNP - single nucleotide polymorphism; HWE - Hardy-Weinberg Equilibrium; $x^{2}$ - Chi square; $p<0.05$ - significant value

Table 2. Comparison of serum vitamin D levels (25-OHD) with studied VDR polymorphisms

\begin{tabular}{|l|c|c|}
\hline VDR genotype & $\begin{array}{c}25(\mathrm{OH}) \mathrm{D} \\
\text { Mean (SD) }\end{array}$ & p-value \\
\hline rs2228570 & \multicolumn{2}{|l|}{} \\
\hline CC & $28.6(8.7)$ & 0.029 \\
\hline CT + TT & $22.1(8.5)$ & \\
\hline rs731236 & 0.683 \\
\hline TT & $26.9(10.3)$ & \\
\hline TC + CC & $28.2(5.0)$ & 0.098 \\
\hline rs1544410 & $24.3(9.1)$ & \\
\hline AA & $29.0(7.6)$ & \\
\hline AG + GG & $24.7(8.9)$ & 0.128 \\
\hline rs7975232 & $29.5(7.9)$ & \\
\hline AA & \\
\hline AC + CC &
\end{tabular}

$p<0.05-$ significant value on t-test

\section{DISCUSSION}

Vitamin D deficiency is currently a worldwide problem, affecting people in many different ways including skeletal problems, immune system deficiencies, depression, and cardiovascular disease. Metabolically active vitamin D exerts its effects by binding to its receptor, VDR, in the nuclei of target cells. Activated receptors initiate expression of genes involved in calcium homeostasis, keratinocyte differentiation, bile acid metabolism and immune metabolism by directly binding to the hormone response elements (HREs). Living in high latitudes, exposure to limited sunlight, high age, and sedentary lifestyle are known factors, which increase the risk of vitamin D deficiency. In addition to these, variations in the VDR gene and encoding the vitamin D receptor have also been identified as risk factors. Cyprus, as a Mediter- ranean island, receive constant sunlight all months throughout the year and Mediterranean diet is generally rich in foods with vitamin D. However, in recent years it has been revealed that a high percentage of the Northern Cypriot population suffer from vitamin D deficiency. This suggests that other factors rather than sunlight exposure and diet are affecting vitamin D levels. In this context, associations between vitamin D levels and common VDR polymorphisms in 131 Turkish Cypriots, aged between 18 and 40 , were investigated in this study.

VDR variants studied in the project were rs2228570 $\mathrm{C}>\mathrm{T}$, rs $731236 \mathrm{~T}>\mathrm{C}$, rs $1544410 \mathrm{G}>\mathrm{A}$, and rs $7975232 \mathrm{~A}>\mathrm{C}$. These are the most widely studied variations of the VDR and were previously associated with increased risk of certain diseases. Namely, rs2228570 is associated with chronic kidney disease, low back pain and ovarian cancer (19-21). Rs731236 was shown to be associated with restless leg syndrome and prostate cancer risk $(22,23)$. Rs 1544410 is linked to increased risk for adolescent idiopathic scoliosis and multiple primary melanoma $(24,25)$. Rs7975232 is associated with chronic obstructive pulmonary disease and risk of developing osteoporosis in certain populations (26).

Allele frequencies of these four variants in the studied group were in agreement with the Hardy-Weinberg equilibrium and the frequencies were concordant with global and TSI (Tuscany, Italia) populations, which were reported in ENSEMBL database. No significant association between having low vitamin $\mathrm{D}$ levels and carrying the rs $731236 \mathrm{~T}>\mathrm{C}$, rs $1544410 \mathrm{G}>\mathrm{A}$ and $\mathrm{rs} 7975232 \mathrm{~A}>\mathrm{C}$ polymorphisms was detected. On the other hand, rs2228570 C $>\mathrm{T}$ was shown to be significantly associated with low serum vitamin $\mathrm{D}$ levels in the studied population. These results are in agreement with our previous study (27). Interestingly, the effect of vitamin D deficiency is seen more frequently in younger people within the population. As until 1980s, almost all Cypriots were dependent on agriculture and farming facilities for living, which was also highly encouraged by the government during the British colonization (28). Therefore, people were exposed to more sunlight. Hypothetically, this way it was possible for them to compensate the lack of vitamin D caused by the presence of the polymorphism. 
However, for the last few decades most of the Turkish Cypriots started to work as from nine-to-five office workers, spending their time inside buildings and therefore receiving much less sunlight. This variant, which allows them to survive under heavy sun light conditions, has become a major disadvantage and an important health problem at present. Additionally, the study indicated that almost all patients admitted to the hospital suffering from the symptoms of vitamin D deficiency are young professionals, who work in a nine-to-five office routine. The results well explain the typical natural selection scenario, however, further studies with a larger cohort and experiments to describe the molecular effect of the detected variant can improve our understanding of the subject.

\section{CONCLUSION}

Together with the presence of the VDR gene polymorphism, the significant change in the lifestyle of population is most likely the main reason of higher numbers of young patients suffering from the outcomes of low vitamin D levels in the studied cohort of Turkish Cypriot population.

\section{Conflict of Interests}

None declared

\section{Adherence to Ethical Standards}

All procedures performed in studies involving human participants were in accordance with the ethical standards of the Institutional Scientific Research Ethic Committee (NEU/2019/70/857) and with the 1964 Helsinki Declaration and its later amendments or comparable ethical standards. Informed consent was obtained from all participants included in the study.

\section{REFERENCES}

1. Holick MF. Vitamin D deficiency. N Engl J Med. 2007;357(3):266-81.

2. Sizar O, Khare S, Goyal A, Bansal P, Givler A. Vitamin D deficiency [Internet]. Treasure Island: StatPearls Publishing; 2021 [cited 2021 Jan 25]. Available from: https://www.ncbi.nlm.nih.gov/books/NBK532266/.

3. Bierschenk L, Alexander J, Wasserfall C, Haller M, Schatz D, Atkinson M. Vitamin D levels in subjects with and without type 1 diabetes residing in a solar rich environment. Diabetes Care. 2009;32(11):1977-9.

4. Grant WB. Roles of solar UVB and Vitamin D in reducing cancer risk and increasing survival. Anticancer Res. 2016;36(3):1357-70.

5. Pilz S, Gaksch M, O'Hartaigh B, Tomaschitz A, Marz W. The role of vitamin D deficiency in cardiovascular disease: where do we stand in 2013? Arch Toxicol. 2013;87(12):2083-103.

6. Holick MF. Vitamin D: important for prevention of osteoporosis, cardiovascular heart disease, type 1 diabetes, autoimmune diseases, and some cancers. South Med J. 2005;98(10):1024-7.

7. Di Monaco M, Castiglioni C, Tappero R. Parathyroid hormone response to severe vitamin D deficiency is associated with femoral neck bone mineral density: an observational study of 405 women with hip-fracture. Hormones (Athens). 2016;15(4):527-33.

8. Gatti D, Idolazzi L, Fassio A. Vitamin D: not just bone, but also immunity. Minerva Med. 2016;107(6):452-60.

9. Makishima M. Bone and calcium metabolism associated with malignancy. Vitamin D and cancer. Clin Calcium. 2018;28(11):1465-72. (In Japanese.)

10. Manson JE, Cook NR, Lee IM, Christen W, Bassuk SS, Mora S, et al Vitamin D supplements and prevention of cancer and cardiovascular disease. N Engl J Med. 2019;380(1):33-44.
11. Palacios C, Gonzalez L. Is vitamin D deficiency a major global public health problem? J Steroid Biochem Mol Biol. 2014;144 Pt A:138-45.

12. Atoum M, Alzoughool F. Vitamin D and breast cancer: latest evidence and future steps. Breast Cancer (Auckl). 2017;11:1178223417749816. doi: $10.1177 / 1178223417749816$.

13. Hohaus S, Tisi MC, Bellesi S, Maiolo E, Alma E, Tartaglia G, et al. Vitamin D deficiency and supplementation in patients with aggressive B-cell lymphomas treated with immunochemotherapy. Cancer Med. 2018;7(1):270-81.

14. Grant WB. Vitamin D and health in the Mediterranean countries. Hormones (Athens). 2019;18(1):23-35

15. Goring H, Koshuchowa S. Vitamin D Deficiency in Europeans today and in Viking settlers of Greenland. Biochemistry (Mosc). 2016;81(12):14927.

16. Lee WC, Mokhtar SS, Munisamy S, Yahaya S, Rasool AHG. Vitamin D status and oxidative stress in diabetes mellitus. Cell Mol Biol (Noisy-legrand). 2018;64(7):60-9

17. Ban Y, Taniyama M, Yanagawa T, Yamada S, Maruyama T, Kasuga A, et al. Vitamin D receptor initiation codon polymorphism influences genetic susceptibility to type 1 diabetes mellitus in the Japanese population. BMC Med Genet. 2001;2:7. doi: 10.1186/1471-2350-2-7.

18. 18.Chang TJ, Lei HH, Yeh JI, Chiu KC, Lee KC, Chen MC, et al. Vitamin $\mathrm{D}$ receptor gene polymorphisms influence susceptibility to type 1 diabetes mellitus in the Taiwanese population. Clin Endocrinol (Oxf). 2000;52(5):575-80.

19. Chen H, Zhu J. Vitamin D receptor rs 2228570 polymorphism and susceptibility to ovarian cancer: an updated meta-analysis. J Obstet Gynaecol Res. 2018;44(3):556-65.

20. Cauci S, Migliozzi F, Trombetta CS, Venuto I, Saccheri P, Travan L, et al. Low back pain and FokI (rs2228570) polymorphism of vitamin D receptor in athletes. BMC Sports Sci Med Rehabil. 2017;9:4. doi: 10.1186/ s13102-017-0069-x.

21. Zhou TB, Jiang ZP, Huang MF, Su N. Association of vitamin D receptor Fok1 (rs2228570), TaqI (rs731236) and ApaI (rs7975232) gene polymorphism with the risk of chronic kidney disease. J Recept Signal Transduct Res. 2015;35(1):58-62.

22. Jiménez-Jiménez FJ, García-Martín E, Alonso-Navarro H, Martínez C, Zurdo M, Turpín-Fenoll L, et al. Association between Vitamin D Receptor rs731236 (Taq1) polymorphism and risk for restless legs syndrome in the Spanish Caucasian Population. Medicine (Baltimore). 2015;94(47):e2125. doi: 10.1097/MD.0000000000002125.

23. Liu S, Cai H, Cheng W, Zhang H, Pan Z, Wang D. Association of VDR polymorphisms (Taq I and Bsm I) with prostate cancer: a new metaanalysis. J Int Med Res. 2017;45(1):3-10.

24. Yin X, Wang H, Guo J, Zhang L, Zhang Y, Li L, et al. Association of vitamin D receptor BsmI rs1544410 and ApaI rs7975232 polymorphisms with susceptibility to adolescent idiopathic scoliosis: A systematic review and meta-analysis. Medicine (Baltimore). 2018;97(2):e9627. doi: 10.1097/MD.0000000000009627.

25. Mandelcorn-Monson R, Marrett L, Kricker A, Armstrong BK, Orlow I, Goumas C, et al. Sun exposure, vitamin D receptor polymorphisms FokI and BsmI and risk of multiple primary melanoma. Cancer Epidemiol. 2011;35(6):e105-10.

26. Kim SW, Lee JM, Ha JH, Kang HH, Rhee CK, Kim JW, et al. Association between vitamin D receptor polymorphisms and osteoporosis in patients with COPD. Int J Chron Obstruct Pulmon Dis. 2015; 10:1809-17.

27. Tuncel G, Temel SG, Ergoren MC. Strong association between VDR FokI (rs2228570) gene variant and serum vitamin D levels in Turkish Cypriots. Mol Biol Rep. 2019;46(3):3349-55.

28. Tozan A, Akın G. Urbanization and architectural developments in North Cyprus during British colonial and postcolonial periods. Itudergisi. 2009;8(2):57-68. (In Turkish.)

Received January 29, 2020 Accepted in revised form January 25, 2021 